\title{
IL-17 Inhibition in Axial Spondyloarthritis
}

\author{
Abhijeet Danve, $M D^{1, *}$ \\ Atul Deodhar, MD, MRCP ${ }^{2}$
}

\author{
Address \\ *,1Division of Rheumatology, University of Nebraska Medical Center, 983025 \\ Nebraska Medical Center, Omaha, NE 68198-3025, USA \\ Email: drdanve@hotmail.com \\ ${ }^{2}$ Division of Arthritis \& Rheumatic Diseases, Oregon Health \& Science University, \\ 3181 SW Sam Jackson Park Rd, Portland, OR 97239, USA
}

Published online: 2 April 2015

(C) Springer International Publishing AG 2015

This article is part of the Topical Collection on Spondyloarthritis and Psoriatic Arthritis

Abhijeet Danve is a rheumatology research fellow.

Atul Deodhar is a professor of medicine.

Final manuscript has been approved by all the authors, and they confirm the integrity of the work.

Keywords Interleukin-17 - Interleukin-17 inhibitors - Th17 cells · Interleukin-23 · Ankylosing spondylitis · Axial spondyloarthritis · Ustekinumab

\section{Opinion statement}

Axial spondyloarthritis (axSpA) affects $0.5-1.5 \%$ of western population. Although TNF inhibitor (TNFi) medications have dramatically improved the treatment of this disabling disease, there are almost $40 \%$ of patients who do not respond or have intolerance to TNFi. Several genetic, animal model, translational, and clinical studies have confirmed the role of IL23/IL-17 pathway in the pathogenesis of the axSpA. This axis could be targeted upstream by inhibiting either IL-23 or IL-23 receptor (IL-23R) or downstream by blocking IL-17 or IL-1RA receptor. Ustekinumab, a monoclonal antibody against p40 subunit of IL-12 and IL-23, and secukinumab, a monoclonal antibody against IL-17, have both demonstrated significant beneficial effect in controlling the disease activity, quality of life, and physical function as well as MRI scores in axSpA. Combined IL-17 and TNF- $\alpha$ blockade is a novel option for the patients with axSpA, which needs to be investigated further. We need prospective trials to evaluate the effect of IL-23/IL-17 axis manipulation on the radiographic progression and also on the extra-articular manifestations of axSpA.

\section{Introduction}

Axial spondyloarthritis (axSpA) is an immunemediated chronic inflammatory disease affecting the axial and peripheral skeleton as well as extra-articular organs such as the skin, gut, and eyes. It is estimated 
that $0.5-1.5 \%$ of the population in the western hemisphere is affected by axSpA [1]. With better understanding of the underlying immunopathogenesis, newer targeted therapies are being developed to treat this condition.

TNF inhibitors (TNFi) dramatically improve the symptoms and functional capacity and reduce the disease activity in patients with axSpA [2-6]. Studies with different TNFi show ASAS 20 (Assessment of Spondyloarthritis International Society criterion 20) responses to be about $60 \%$ and ASAS 40 responses to be $40 \%$. Approximately $20 \%$ of patients reach ASAS partial remission. This implies that a significant number of patients either do not respond to, or only partially respond TNFi. Many patients may develop either loss of efficacy or intolerance to these medications over time. It is still unclear if TNFi slow the new bone formation in patients with axSpA; however, recent studies demonstrate favorable results
[7•]. All of these issues underscore the importance of investigating other pathogenic mechanisms of spondyloarthritis.

Non-TNF-directed biologic agents used in the treatment of rheumatoid arthritis such as anakinra, abatacept, rituximab, and tocilizumab have been tried in axSpA with disappointing results [8-12].

Recent years have seen much progress in understanding the IL-23/IL-17 axis and its role in the pathogenesis of many immune-mediated inflammatory diseases such as multiple sclerosis, psoriasis, and inflammatory bowel disease. Growing evidence from genetic, animal, translational, and clinical studies has confirmed the role of IL-23/IL-17 axis in the pathogenesis of axSpA as well. In this review, we will discuss the role of IL-23/IL-17 axis in the pathogenesis of axSpA and describe how this axis can be successfully manipulated for treatment of this condition.

\section{IL-23/IL-17 axis}

\section{IL-23}

IL-23 is secreted by activated macrophages and dendritic cells as a heterodimer that comprises a unique p19 subunit, and a common p40 subunit shared with IL-12 $[13,14]$. IL-23 binds to IL-23 receptor (IL-23R) on IL-23R-expressing cells, particularly Thelper 17 (Th17) cells, innate lymphoid cells like $\gamma \delta$ (gamma delta) T cells and invariant natural killer T (iNKT) cells. Engagement of IL-23 with the IL-23R complex composed of IL-23R and IL-12Rb1 leads to activation of these cells through the signal transducer and activator of transcription 3' (STAT3) pathway. In response to the intracellular STAT3 signaling, there is upregulation of retinoic acid receptor-related orphan receptor (ROR)- $\gamma$ and ROR- $\alpha$ transcription regulators, which are essential for the effector cells to secrete IL-17A and IL-17F. Of note, IL$23 \mathrm{R}$ is not present on naïve T cells, so the main role of IL-23 is terminal differentiation and maintenance of Th17 cells rather than development. IL-23 is now recognized to be essential for the proliferation and terminal differentiation of CD4+ Th17 cells, maintaining IL-17 production and ultimately driving the pathogenicity of these cells in multiple models of autoimmunity $[12,13,15,16 \bullet]$.

Th17 cells are a unique subset of CD4+ T cells discovered in 2005, characterized by their ability to secrete IL-17, a potent pro-inflammatory cytokine and also other distinct cytokines such as IL-21 and IL-22 [17••, 18, 19]. In health, Th17 cells play a prominent role in the clearance of pathogens that are not adequately handled by Th1 or Th2 cells. They are also potent inducers of tissue inflammation and have been associated with the pathogenesis of many experimental autoimmune diseases and human inflammatory conditions such as multiple sclerosis, psoriasis, rheumatoid arthritis, and ankylosing spondylitis [20]. TGF- $\beta$, IL-6, and IL-21 act as differentiation factors; IL-23 acts as a growth and stabilization factor; and STAT3, 
ROR- $\gamma$, and ROR- $\alpha$ act as transcription factors for the development of Th17 cells [20]. Th17 cells demonstrate significant plasticity. Depending upon the cytokines or pathogens present in the tissues, Th17 cells can differentiate into interferon (IFNy)-producing Th1 cells or IL-4-producing Th2 cells [21].

IL-17 cytokine family members are the signature cytokines secreted by Th17 cells. Since their discovery, Th17 cells and the cytokines they produce have been implicated in nearly all major autoimmune syndromes. Th17 cells secrete IL17A and IL-17F which are two of the six highly conserved cytokines (IL-17A-F) in the IL-17 cytokine family. The cytokine IL-17A was discovered in 1993 [22]. IL-17A is commonly described as IL-17, as it is the most influential of the IL-17

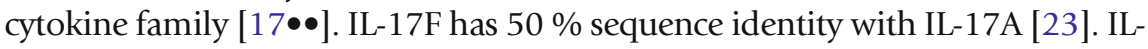
17A and IL-17F are both covalent homodimers, but the single subunits can also form IL-17A-IL-17F heterodimers [23]. IL-17A, IL-17F, and IL-17A-IL-17F all signal through a heteromeric receptor complex consisting of the IL-17RA and IL17RC subunits, mainly expressed on epithelial, endothelial, and fibroblast cells resulting in activation of nuclear factor kappa-light-chain-enhancer of activated $\mathrm{B}$ cells (NF-kB) pathway, which then leads to the production of proinflammatory cytokines such as IL-6, IL-8, TNF- $\alpha$, matrix metalloproteinases, and RANKL in a variety of target cells from fibroblasts to epithelial and endothelial cells, macrophages, dendritic cells (DCs), chondrocytes, and osteoblasts thereby playing an important protective role in mucosal immunity to bacteria and fungi, but also promoting inflammation and bone and cartilage destruc-

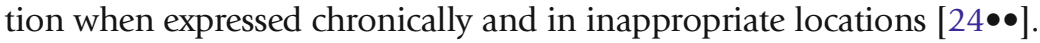

IL-17 and TNF- $\alpha$ have synergistic relation with each other, where IL-17 augments the effect of TNF- $\alpha$ in part by enhancing the expression of TNF receptor 2 (TNFR2) [25] and TNF- $\alpha$ enhances the effect of IL-17 on mRNA stability, leading to increased levels of protein expression. Miossec et al. have proposed that IL-17 could be targeted in the subsets of patients with inflammatory diseases who are not responsive (or insufficiently responsive) to TNFi and, also, the combination of TNFi and IL-17 inhibitors could represent a new approach to control the interactions between the two cytokines in inflammatory disorders [51 $\bullet$ ]. Synergistic interactions also occur between IL-17 and IL- 1 . Th17 cells also produce other proinflammatory cytokines including IL-6, TNF, IL-22, and IL-21 [17••].

Other sources of IL-17

Innate lymphoid cells are the major contributor of IL-17 in humans, rather than Th17 cells $[26,27]$. Innate T cells like $\gamma / \delta$ T cells and iNKT cells upon activation by IL-1 and IL-23 can produce IL-17 independent of TCR-MHC complex engagement [26]. Natural killer cells, mast cells, and neutrophils are some other sources of IL-17. Most of these cell types are activated by IL-23, which can be produced by DCs and macrophages exposed to microbial products. This suggests that IL-23/IL-17 axis can influence the disease even in the absence of Th17 cells.

\section{Role of IL-23/IL-17 axis in axSpA}

Multiple genetic, animal model, translational, and clinical studies have confirmed the role of the IL-23/IL-17 axis in the pathogenesis of axSpA, mainly in ankylosing spondylitis. 
Several genetic studies point to the involvement of IL-23/IL-17 axis in the pathogenesis of ankylosing spondylitis. IL-23R gene variant rs11209026 (Arg381Gln) offers protection against IBD [28], psoriasis [29], and ankylosing spondylitis [30] through selective impairment of IL-17A production [15] due to decreased STAT3 phosphorylation [31]. Several other genes including CARD9, IL-12B, IL-6R, IL-27, TYK2, and STAT3 have been implicated in ankylosing spondylitis (AS) and also are

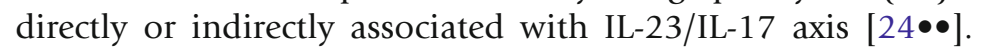

In the rat model overexpression of HLA-B27 (and human $\beta 2$-microglobulin) is sufficient to result in activation and accumulation of CD4+ Th17 cells in the gut [18] and affected joints [32].

Animal experiments also show that HLA-B27 misfolding leads to endoplasmic reticulum (ER) stress, resulting in unfolded protein response in macrophages and increased release of IL-23 from activated macrophages as well as upregulation of IL- 6 and TNF- $\alpha$ expression [32-35].

HLA-B27 molecule has an unusual property of formation of homodimers on the cell surface. Homodimers of HLA-B27 heavy chain have shown to promote survival of innate lymphoid cells, particularly Th17 cells expressing killer cell Ig-like receptor, KIR3DL2, which then secrete increased quantities of IL-17 [36]. Ligation of KIR3DL2 receptors by HLA-B27 molecules enhances the survival of NK and Th17 cells.

Enthesitis is considered to be the primary pathology in patients with various spondyloarthritides [37]. In the pioneering work on IL-23overexpressing transgenic mice, Sherlock et al. found a unique type of $\mathrm{T}$ cells that were IL-23R+ ROR- $\gamma \mathrm{t}+\mathrm{CD} 3+\mathrm{CD} 4-\mathrm{CD} 8-$, and they were present in the entheses, aortic root, and uvea. These cells, upon activation with IL-23, secrete IL-17A, IL-17F, IL-6, and IL-22, which led to axial and peripheral inflammatory arthritis followed by IL-22-dependent osteoproliferation, suggesting the role of IL-22 in the new bone formation in the axSpA $[38 \bullet \bullet]$.

Human studies show elevated serum and synovial fluid IL-17 and also IL-23

levels in patients with AS and PsA, but their association with disease activity and response to TNFi has been inconsistent [39-42].

The number of Th17 and Th22 cells is also elevated in the peripheral blood of patients with AS and, upon ex vivo stimulation of PBMCs, secreted elevated levels of IL-17 [43, 44].

Similar to animal studies, Bowness et al. found increased numbers of innate $\mathrm{T}$ cells expressing KIR3DL2 in the peripheral blood and synovial fluid of patients with AS [36]. Also, there is evidence of increased IL-17 expression at the tissue levels by non-lymphoid cells like mast cells in the synovium of peripheral joints [45] and by neutrophils in the facet joints in patients with SpA [46]. IL-23 is overexpressed in the bone marrow of AS patients mainly by the myeloid cells and macrophages as compared to facet joints from osteoarthritis patients [46]. All these 
studies point towards the pathogenic role of IL-23/IL-17 axis in the human axial spondyloarthritis.

\section{Clinical trials of medications targeting IL-23/IL-17 axis in axSpA}

\section{Ustekinumab}

A prospective, open-label, single-arm, "proof-of-concept" trial (NCT01330901) of subcutaneous ustekinumab, a fully human monoclonal antibody against common p40 subunit of IL-12 and IL-23, showed beneficial effect in the axial

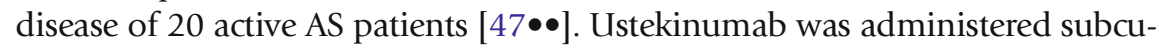
taneously at a dose of $90 \mathrm{mg}$ at baseline, week 4, and week 16 . At 24 weeks, an ASAS 20 response was observed in $75 \%$ of patients, while $30 \%$ of patients reached ASAS partial remission status. There were also significant improvements in other patient-reported outcomes (AS quality of life (ASQoL), EQ-5D) as well as a reduction in the intake of concomitant NSAIDs. There was a significant reduction of active inflammation as scored using the Berlin scoring method ( $41 \%$ for the sacroiliac joints and $31 \%$ for the spine) at week 24 .

Secukinumab is fully human monoclonal antibody against IL-17A. It has been found to be very effective in axSpA in phase II as well as phase III studies.

A randomized double-blind proof-of-concept multicenter phase 2 study [48 $\bullet$ ] (NCT00809159) of IV secukinumab (10 mg/kg, two doses given 3 weeks apart), compared to placebo (PBO), involved 30 patients with moderate-to-severe AS. At week 6, ASAS 20 response was $59 \%$ in secukinumab group ( $n=23)$ compared to $24 \%$ with placebo $(n=6)$. The mean MRI scores decreased from 9.2 (SD 8.87) at baseline to $5.7(6.20)$ at week 28 ( $p=n s)$ in the secukinumab group but remained unchanged in the placebo group at week 28 . The clinical response to secukinumab was also significantly associated with genetic polymorphisms in ERAP1 and showed a trend towards the association with polymorphisms in IL-23R.

The results of two phase 3, randomized, placebo-controlled trials with subcutaneous secukinumab, MEASURE 1 and MEASURE 2, were presented at the 2014 annual meeting of the American College of Rheumatology (ACR).

MEASURE 1 study (NCT01358175) was a 52-week randomized placebocontrolled trial with intravenous loading and subcutaneous maintenance dosing

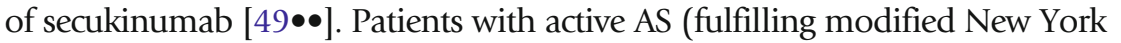
Criteria and Bath Ankylosing Spondylitis Disease Activity Index (BASDAI) >4), despite current or previous therapy with NSAIDs, DMARDs, and/or TNFi, were randomized into three groups: secukinumab IV loading dose $(10 \mathrm{mg} / \mathrm{kg})$ at 0.2 and 4 weeks followed by $75 \mathrm{mg} \mathrm{SC}$ (group A, $n=124$ ) or $150 \mathrm{mg} \mathrm{SC}$ (group B, $n=125$ ) every 4 weeks or PBO (group C, $n=122$ ). Non-responder PBO patients (pts) were re-randomized to secukinumab 75 or $150 \mathrm{mg}$ at week 16 and all other PBO patients at week 24. Endpoints included ASAS 20 at week 16 (primary), ASAS 40, hsCRP, ASAS 5/6, BASDAI, and ASAS partial remission.

At week 16, secukinumab groups had significantly higher ASAS 20 responses (group A, $59.7 \%$, and group B, $60.8 \%$ ) compared to PBO (group C, $28.7 \%$, $p<0.01$ ). ASAS 20 response rates in TNF-naïve pts were 60.0, 66.3, and $32.6 \%$, and in the TNF-IR pts, these were $58.8,45.5$, and $18.2 \%$, in groups A, B, and C, 


\section{Conclusion}

respectively ( $p=0.01$ vs. $\mathrm{PBO}$ ). Secukinumab groups A and B achieved all the pre-specified secondary outcomes, and the responses were sustained through week 52. The onset of action of secukinumab was as rapid as 1 week.

Secukinumab was generally well tolerated. The most common adverse events were upper respiratory tract infection and headache.

Patient-reported outcomes were measured every 4 weeks in the MEASURE 1 study using short-form 36 (SF-36), EuroQoL (EQ-5D), ASQoL, Functional Assessment of Chronic Illness Therapy-Fatigue (FACIT-Fatigue), and Work Productivity and Activity Impairment-General Health (WPAI-GH) [49••]. Secukinumab significantly improved scores on the SF-36 physical and mental component summaries, ASQoL, EQ-5D, and FACIT-Fatigue versus PBO at week 16. The mean changes from baseline at week 16 were greater than the minimum clinically important difference (MCID) for SF-36.

In the second randomized, multicenter, double-blind, $\mathrm{PBO}$-controlled, phase 3 trial (MEASURE 2; NCT01649375), adult patients with active AS (BASDAI >4) despite adequate NSAIDS were randomized to receive weekly SC secukinumab 75 and $150 \mathrm{mg}$ or PBO for 4 weeks followed by dosing every 4 weeks [49••]. They included a total of 219 patients with inadequate response or intolerance to TNFi (38.4 \%) as well as TNFi-naïve patients (61.6\%) with mean disease duration of 6.9 years and mean BASDAI of 6.65 . While secukinumab $75 \mathrm{mg}$ did not achieve the pre-specified primary or secondary endpoints, secukinumab $150 \mathrm{mg}$ achieved $61.7 \%$ ASAS 20 response compared to $27 \%$ with PBO ( $p=0.001)$ at week 16. Secukinumab $150 \mathrm{mg}$ also significantly improved hsCRP, ASAS 40, ASAS 5/6, BASDAI, SF-36 PCS, and ASQoL compared with PBO. Secukinumab 150 mg was found to be useful in both TNF-naïve (ASAS 20 response 68.9 vs. $31.1 \%$ in PBO; ASAS 40 response 44.4 vs. $17.8 \%$ ) and TNF-IR (ASAS 2048.1 vs. $20.7 \%$ in PBO; ASAS 40 response 22.2 vs. $0 \%$ ) patients. The risk of serious adverse effects is comparable in all the three groups $(5.5,5.6$, and $4.1 \%)$.

The substantial evidence from genetic, animal model, and human studies as well as from clinical trials confirms the role of the Th17-dependent and Th17independent IL-23/IL-17 pathway in the pathogenesis of axSpA. This information provides exciting novel pathogenic targets for the treatment of patients with axSpA who are not responding to, or only partially responding to, the available treatments like NSAIDs and TNFi (see Table 1). Initial proof-ofconcept studies of ustekinumab and secukinumab showed significant benefit in the patients with active AS. Both these molecules also showed improvement in

\section{Table 1. Currently available therapeutic targets and biologic agents targeting IL-23/IL-17 pathway}

\begin{tabular}{ll}
\hline Mechanism of action & Drug \\
Monoclonal antibody against p40 subunit of IL-12 and IL-23 & Ustekinumab \\
Monoclonal antibody against p19 subunits of IL-23 & Tildrakizumab, guselkumab \\
Monoclonal antibody against IL-17A & Secukinumab, ixekizumab \\
Monoclonal antibody against IL-17RA & Brodalumab \\
Monoclonal antibody against IL-22 & Fezakinumab \\
Small molecule suppressing the synthesis of IL-23 and IL-12 & Apilimod
\end{tabular}


the MRI changes of inflammation after the treatment in the proof-of-concept studies.

With the recent phase 3 studies on secukinumab (Measure 1 and Measure 2), it is clearly evident that IL-17A inhibition results in quick and long-lasting improvement in the symptoms and signs of AS as well as significant improvement in physical function and quality of life.

It would be interesting to see if a blockade of IL-17RA receptor with brodalumab gives similar results as IL-17A inhibition in axSpA. Brodalumab has been found very effective in improving PASI scores as well as response rates of psoriatic arthritis [50]. As IL-17A acts synergistically with TNF- $\alpha$, IL-6, and also IL-1, it may be possible to combine TNFi and IL-17A inhibition simultaneously to achieve better control of the inflammation by targeting both the inflammatory pathways. In fact, Fischer et al. in a recent study demonstrated that bispecific anti-TNF/IL-17 antibodies were more effective in inhibiting the cytokine, chemokine, and matrix enzyme responses from human mesenchymal cells in vitro. This study also showed that dual (both IL17 and TNF- $\alpha$ ) versus single (either IL-17 or TNF- $\alpha$ ) inhibition was more effective in inhibiting the development of inflammation and bone and cartilage destruction in arthritic mice [51•]. As IL-17A forms heterodimers with IL-17F and these heterodimers have similar action as of IL-17A homodimers, it would be interesting to study the role of IL-17RA inhibition, which will block the action of IL-17A and IL17F. Targeting IL-23/IL-17 axis upstream at IL-23 inhibition or IL-23 receptor blockade may also be an option in the treatment of axSpA. It would be worthwhile to monitor the biological and imaging parameters of the new bone formation in patients treated with these medications to evaluate their effect on preventing ankylosis and syndesmophyte formation in axSpA.

\section{Compliance with Ethics Guidelines}

\section{Conflict of Interest}

Abhijeet Danve declares that he has no conflict of interest.

Atul Deodhar reports grants from Amgen, AbbVie, Janssen, Novartis, Pfizer, and UCB and personal fees from Amgen, AbbVie, Janssen, Novartis, Pfizer, and UCB, outside the submitted work, and Dr. Deodhar has received research grants to conduct studies on secukinumab, a drug described in the manuscript. He is also an author on the published studies on secukinumab and has served on the Advisory Boards for Novartis, the company that owns the drug.

Human and Animal Rights and Informed Consent This article does not contain any studies with human or animal subjects performed by any of the authors.

\section{References and Recommended Reading}

Papers of particular interest, published recently, have been highlighted as:

- Of importance

$\bullet$ Of major importance

1. Reveille JD, Witter JP, Weisman MH. Prevalence of axial spondylarthritis in the United States: estimates from a cross-sectional survey. Arthritis Care Res (Hoboken). 2012;64(6):905-10.
2. van der Heijde D, Dijkmans B, Geusens P, Sieper J, DeWoody K, Williamson P, et al. Efficacy and safety of infliximab in patients with ankylosing spondylitis: results of a randomized, placebo-controlled 
trial (ASSERT). Arthritis Rheum. 2005;52(2):58291.

3. van der Heijde D, Kivitz A, Schiff MH, Sieper J, Dijkmans BA, Braun J, et al. Efficacy and safety of adalimumab in patients with ankylosing spondylitis: results of a multicenter, randomized, double-blind, placebo-controlled trial. Arthritis Rheum. 2006;54(7):2136-46.

4. Li ZH, Zhang Y, Wang J, Shi ZJ. Etanercept in the treatment of ankylosing spondylitis: a meta-analysis of randomized, double-blind, placebo-controlled clinical trials, and the comparison of the Caucasian and Chinese population. Eur J Orthop Surg Traumatol. 2013;23(5):497-506.

5. Inman RD, Davis Jr JC, Heijde D, Diekman L, Sieper J, Kim SI, et al. Efficacy and safety of golimumab in patients with ankylosing spondylitis: results of a randomized, double-blind, placebo-controlled, phase III trial. Arthritis Rheum. 2008;58(11):3402-12.

6. Landewe R, Braun J, Deodhar A, Dougados M, Maksymowych WP, Mease PJ, et al. Efficacy of certolizumab pegol on signs and symptoms of axial spondyloarthritis including ankylosing spondylitis: 24week results of a double-blind randomised placebocontrolled phase 3 study. Ann Rheum Dis.

2014;73(1):39-47.

7. Haroon N, Inman RD, Learch TJ, Weisman MH, Lee M, Rahbar $\mathrm{MH}$, et al. The impact of tumor necrosis factor alpha inhibitors on radiographic progression in ankylosing spondylitis. Arthritis Rheum.

2013;65(10):2645-54.

This multicenter study demonstrated a role of TNFI in preventing the radiographic progression of AS.

8. Sieper J, Porter-Brown B, Thompson L, Harari O, Dougados M. Assessment of short-term symptomatic efficacy of tocilizumab in ankylosing spondylitis: results of randomised, placebo-controlled trials. Ann Rheum Dis. 2014;73(1):95-100.

9. Song IH, Heldmann F, Rudwaleit M, Listing J, Appel H, Braun J, et al. Different response to rituximab in tumor necrosis factor blocker-naive patients with active ankylosing spondylitis and in patients in whom tumor necrosis factor blockers have failed: a twenty-four-week clinical trial. Arthritis Rheum. 2010;62(5):1290-7.

10. Song IH, Heldmann F, Rudwaleit M, Haibel H, Weiss A, Braun J, et al. Treatment of active ankylosing spondylitis with abatacept: an open-label, 24-week pilot study. Ann Rheum Dis. 2011;70(6):1108-10.

11. Haibel H, Rudwaleit M, Listing J, Sieper J. Open label trial of anakinra in active ankylosing spondylitis over 24 weeks. Ann Rheum Dis. 2005;64(2):296-8.

12. Tan $\mathrm{AL}$, Marzo-Ortega $\mathrm{H}, \mathrm{O}^{\prime}$ Connor $\mathrm{P}$, Fraser $\mathrm{A}$, Emery P, McGonagle D. Efficacy of anakinra in active ankylosing spondylitis: a clinical and magnetic resonance imaging study. Ann Rheum Dis. 2004;63(9):1041-5.

13. Tang C, Chen S, Qian H, Huang W. Interleukin-23: as a drug target for autoimmune inflammatory diseases. Immunology. 2012;135(2):112-24.
14. Gee K, Guzzo C, Che Mat NF, Ma W, Kumar A. The IL12 family of cytokines in infection, inflammation and autoimmune disorders. Inflamm Allergy Drug Targets. 2009;8(1):40-52.

15. Di Meglio P, Di Cesare A, Laggner U, Chu CC, Napolitano L, Villanova F, et al. The IL23R R381Q gene variant protects against immune-mediated diseases by impairing IL-23-induced Th17 effector response in humans. PLoS One. 2011;6(2):e17160.

16. Zuniga LA, Jain R, Haines C, Cua DJ. Th17 cell development: from the cradle to the grave. Immunol Rev. 2013;252(1):78-88.

This article provides an excellent overview of Th17 cells and role of IL-23 in the differentiation of Th17 cells.

17.• Miossec P, Korn T, Kuchroo VK. Interleukin-17 and type 17 helper T cells. N Engl J Med. 2009;361(9):88898.

This is an excellent review of IL-17 and its role.

18. Frleta M, Siebert S, McInnes IB. The interleukin-17 pathway in psoriasis and psoriatic arthritis: disease pathogenesis and possibilities of treatment. Curr Rheumatol Rep 2014 Apr;16(4):414,014-0414-y.

19. van den Berg WB, McInnes IB. Th17 cells and IL-17 a-focus on immunopathogenesis and immunotherapeutics. Semin Arthritis Rheum. 2013;43(2):158-70.

20. Korn T, Bettelli E, Oukka M, Kuchroo VK. IL-17 and Th17 cells. Annu Rev Immunol. 2009;27:485-517.

21. Lee YK, Turner H, Maynard CL, Oliver JR, Chen D, Elson CO, et al. Late developmental plasticity in the T helper 17 lineage. Immunity. 2009;30(1):92-107.

22. Rouvier E, Luciani MF, Mattei MG, Denizot F, Golstein P. CTLA-8, cloned from an activated T cell, bearing AUrich messenger RNA instability sequences, and homologous to a herpesvirus saimiri gene. J Immunol. 1993;150(12):5445-56.

23. Wright JF, Guo Y, Quazi A, Luxenberg DP, Bennett F, Ross JF, et al. Identification of an interleukin 17F/17A heterodimer in activated human CD4+ T cells. J Biol Chem. 2007;282(18):13447-55.

$24 . \bullet$ Smith JA, Colbert RA. Review: The interleukin-23/interleukin-17 axis in spondyloarthritis pathogenesis: Th17 and beyond. Arthritis Rheumatol. 2014;66(2):231-41.

This article summarizes in detail about the role of IL-23/IL-17 axis in the pathogenesis of axial spondyloarthritis.

25. Chabaud M, Fossiez F, Taupin JL, Miossec P. Enhancing effect of IL-17 on IL-1-induced IL-6 and leukemia inhibitory factor production by rheumatoid arthritis synoviocytes and its regulation by Th2 cytokines. J Immunol. 1998;161(1):409-14.

26. Sutton CE, Lalor SJ, Sweeney CM, Brereton CF, Lavelle EC, Mills KH. Interleukin-1 and IL-23 induce innate IL17 production from gammadelta $\mathrm{T}$ cells, amplifying Th17 responses and autoimmunity. Immunity. 2009;31(2):331-41.

27. Uhlig HH, McKenzie BS, Hue S, Thompson C, JoyceShaikh B, Stepankova R, et al. Differential activity of IL12 and IL-23 in mucosal and systemic innate immune pathology. Immunity. 2006;25(2):309-18. 
28. Duerr RH, Taylor KD, Brant SR, Rioux JD, Silverberg MS, Daly MJ, et al. A genome-wide association study identifies IL23R as an inflammatory bowel disease gene. Science. 2006;314(5804):1461-3.

29. Cargill M, Schrodi SJ, Chang M, Garcia VE, Brandon R, Callis KP, et al. A large-scale genetic association study confirms IL12B and leads to the identification of IL23R as psoriasis-risk genes. Am J Hum Genet. 2007;80(2):273-90.

30. Wellcome Trust Case Control Consortium, AustraloAnglo-American Spondylitis Consortium (TASC) et al Association scan of 14,500 nonsynonymous SNPs in four diseases identifies autoimmunity variants. Nat Genet. 2007;39(11):1329-37.

31. Sarin R, Wu X, Abraham C. Inflammatory disease protective R381Q IL23 receptor polymorphism results in decreased primary CD4+ and CD8+ human T-cell functional responses. Proc Natl Acad Sci U S A. 2011;108(23):9560-5.

32. DeLay ML, Turner MJ, Klenk EI, Smith JA, Sowders DP, Colbert RA. HLA-B27 misfolding and the unfolded protein response augment interleukin-23 production and are associated with Th17 activation in transgenic rats. Arthritis Rheum. 2009;60(9):2633-43.

33. Turner MJ, Sowders DP, DeLay ML, Mohapatra R, Bai S, Smith JA, et al. HLA-B27 misfolding in transgenic rats is associated with activation of the unfolded protein response. J Immunol.

2005;175(4):2438-48.

34. Turner MJ, Delay ML, Bai S, Klenk E, Colbert RA. HLA-B27 up-regulation causes accumulation of misfolded heavy chains and correlates with the magnitude of the unfolded protein response in transgenic rats: implications for the pathogenesis of spondylarthritis-like disease. Arthritis Rheum. 2007;56(1):215-23.

35. Martinon F, Chen X, Lee AH, Glimcher LH. TLR activation of the transcription factor XBP1 regulates innate immune responses in macrophages. Nat Immunol. 2010;11(5):411-8.

36. Bowness P, Ridley A, Shaw J, Chan AT, Wong-Baeza I, Fleming M, et al. Th17 cells expressing KIR3DL2+ and responsive to HLA-B27 homodimers are increased in ankylosing spondylitis. J Immunol.

2011;186(4):2672-80.

37. Benjamin M, McGonagle D. The enthesis organ concept and its relevance to the spondyloarthropathies. Adv Exp Med Biol. 2009;649:57-70.

38.• Sherlock JP, Joyce-Shaikh B, Turner SP, Chao CC, Sathe M, Grein J, et al. IL-23 induces spondyloarthropathy by acting on ROR-gammat+ CD3+CD4-CD8- entheseal resident T cells. Nat Med. 2012;18(7):1069-76.

This animal study discusses pivotal role of a novel innate lymphoid T cells (IL-23R+ ROR- $\gamma$ t CD3+ CD4- CD8- T cells) present in the entheses, aortic root, and uvea which secrete IL22 and IL-17 in response to the stimulation by IL-23.

39. Chen WS, Chang YS, Lin KC, Lai CC, Wang SH, Hsiao $\mathrm{KH}$, et al. Association of serum interleukin-17 and interleukin-23 levels with disease activity in Chinese patients with ankylosing spondylitis. J Chin Med Assoc. 2012;75(7):303-8.

40. Mei Y, Pan F, Gao J, Ge R, Duan Z, Zeng Z, et al. Increased serum IL-17 and IL-23 in the patient with ankylosing spondylitis. Clin Rheumatol.

2011;30(2):269-73.

41. Wendling D, Cedoz JP, Racadot E, Dumoulin G. Serum IL-17, BMP-7, and bone turnover markers in patients with ankylosing spondylitis. Joint Bone Spine. 2007;74(3):304-5.

42. Xueyi L, Lina C, Zhenbiao W, Qing H, Qiang L, Zhu P. Levels of circulating Th17 cells and regulatory T cells in ankylosing spondylitis patients with an inadequate response to anti-TNF-alpha therapy. J Clin Immunol. 2013;33(1):151-61.

43. Shen H, Goodall JC, Hill Gaston JS. Frequency and phenotype of peripheral blood Th17 cells in ankylosing spondylitis and rheumatoid arthritis. Arthritis Rheum. 2009;60(6):1647-56.

44. Zhang L, Li YG, Li YH, Qi L, Liu XG, Yuan CZ, et al. Increased frequencies of Th22 cells as well as Th17 cells in the peripheral blood of patients with ankylosing spondylitis and rheumatoid arthritis. PLoS One. 2012;7(4):e31000.

45. Noordenbos T, Yeremenko N, Gofita I, van de Sande M, Tak PP, Canete JD, et al. Interleukin-17positive mast cells contribute to synovial inflammation in spondylarthritis. Arthritis Rheum. 2012;64(1):99-109.

46. Appel H, Maier R, Wu P, Scheer R, Hempfing A, Kayser $\mathrm{R}$, et al. Analysis of IL-17(+) cells in facet joints of patients with spondyloarthritis suggests that the innate immune pathway might be of greater relevance than the Th17-mediated adaptive immune response. Arthritis Res Ther. 2011;13(3):R95.

47.•• Poddubnyy D, Hermann KG, Callhoff J, Listing J, Sieper J. Ustekinumab for the treatment of patients with active ankylosing spondylitis: results of a 28-week, prospective, open-label, proof-of-concept study (TOPAS). Ann Rheum Dis. 2014;73(5):817-23.

This study discusses proof of concept trial of ustekinumab in patients with active AS.

48.• Baeten D, Baraliakos X, Braun J, Sieper J, Emery P, van der Heijde D, et al. Anti-interleukin-17A monoclonal antibody secukinumab in treatment of ankylosing spondylitis: a randomised, double-blind, placebocontrolled trial. Lancet. 2013;382(9906):1705-13.

This study discusses proof of concept trial of ustekinumab in patients with active AS.

49.• 2014 ACR/ARHP annual meeting abstract supplement. Arthritis \& Rheumatology 2014;66(S10):S1-S1402. Abstracts 536, 538 and 819.

These are the two randomized phase 3 studies of secukinumab in active AS recently presented at ACR 2014

50. Mease PJ, Genovese MC, Greenwald MW, Ritchlin CT, Beaulieu AD, Deodhar A, et al. Brodalumab, an antiIL17RA monoclonal antibody, in psoriatic arthritis. N Engl J Med. 2014;370(24):2295-306. 
51. Fischer JA, Hueber AJ, Wilson S, Galm M, Baum W, Kitson $\mathrm{C}$, et al. Combined inhibition of tumor necrosis factor alpha and interleukin-17 as a therapeutic opportunity in rheumatoid arthritis: development and characterization of a novel bispecific antibody. Arthritis Rheumatol. 2015;67(1):51-62.

This study discusses possible role of combined TNFI and antiIL-17 construct in the treatment of inflammatory arthritis. 